\title{
Study on Modification of Polymer Properties by the Cold Drawing Process
}

\author{
Wing-Fu Lai \\ Department of Mechanical Engineering, The University of Hong Kong, Hong Kong, China \\ Email: rori0610@graduate.hku.hk
}

Received 22 October 2014; accepted 27 November 2014; published 13 January 2015

Copyright (C 2015 by author and Scientific Research Publishing Inc.

This work is licensed under the Creative Commons Attribution International License (CC BY). http://creativecommons.org/licenses/by/4.0/

c) (i) Open Access

\begin{abstract}
Polymers have a wide diversity of applications, ranging from therapeutics delivery to tissue engineering. While advances in polymer chemistry have facilitated synthesis and development of new polymers, increasing efforts have also been directed to engineer properties of existing polymers. One of the common approaches to modify polymer properties is cold drawing, which can align polymer chains and orient the chains in a crystalline manner. Regarding the industrial significance of cold drawing in polymer engineering, this study used semi-crystalline high density polyethylene (HDPE) as a model to examine the effect of cold drawing on the anisotropic mechanical properties of polymers. During cold drawing, the yield strength of the polymer was shown to be in a positive relationship with the strain rate, and the hardness of the cold-drawn region was demonstrated to be significantly enhanced. Our results confirmed the feasibility of engineering the properties of polymers by applying tension for plastic deformation, and highlighted the importance of precise control of the strain rate in the treatment.
\end{abstract}

\section{Keywords}

Cold Drawing, Mechanical Deformation, Polymers, Strain Rate

\section{Introduction}

Polymers have been imparted with a wide diversity of applications, ranging from therapeutics delivery [1]-[3] to tissue engineering [4], from water vapor barrier packaging [5] to development of sensors [6] [7]. While advances in polymer chemistry have facilitated synthesis of new polymers [8]-[11], increasing efforts have also been paid to engineer the properties of existing polymers for better function and performance. Among different approaches, cold drawing is one of the most extensively studied operations [12]-[18]. As it can align polymer chains and orient the chains in a crystalline manner, cold drawing can directly improve the properties of existing 
polymers, while reducing the labor cost and time taken for new polymer development. Cold drawing, therefore, has major industrial significance in synthetic fiber production. Regarding the practical potential of cold drawing, this study used the semi-crystalline high density polyethylene (HDPE) as a model to examine the effect of cold drawing on the anisotropic mechanical properties of the polymer. It is the objective of this study to shed more light on polymer engineering via cold drawing.

\section{Materials and Methods}

\subsection{Fabrication of HDPE Tensile Bars}

HDPE tensile bars with Type I dimensions as specified in ASTM D 638 were cast via injection molding. $185^{\circ} \mathrm{C}$ was taken as the temperature used in the melting zone during injection molding (BOY 22S, Dipronic).

\subsection{Tensile Tests}

Tensile tests were performed according to earlier studies [19] [20], with the setup being shown in Figure 1. In brief, the Instron tensile testing machine was used in the range of $0-2 \mathrm{kN}$. The maximum load and the drawing force were examined over a range of cross head speeds (5, 50, 80, 100, 200 and $500 \mathrm{~mm} / \mathrm{min})$. The load-extension curve was obtained for each of the cross head speeds adopted. Changes in temperature were examined by slightly touching the drawing tip during the process of cold drawing. The cross-sectional area before and after the cold drawing process was recorded by using a caliper.

\subsection{Hardness Measurement}

The hardness values of the undrawn specimens, as well as those of the necking regions, were examined by using a durometer at ambient conditions according to the ASTM D2240 method as reported in an earlier study [21].

\subsection{Statistical Analysis}

Quantitative data were obtained in triplicate. They were reported as means \pm standard deviations, where indicated. Student's t-test was performed to assess the statistical significance. Differences with p-value $<0.05$ were considered to be statistically significant.
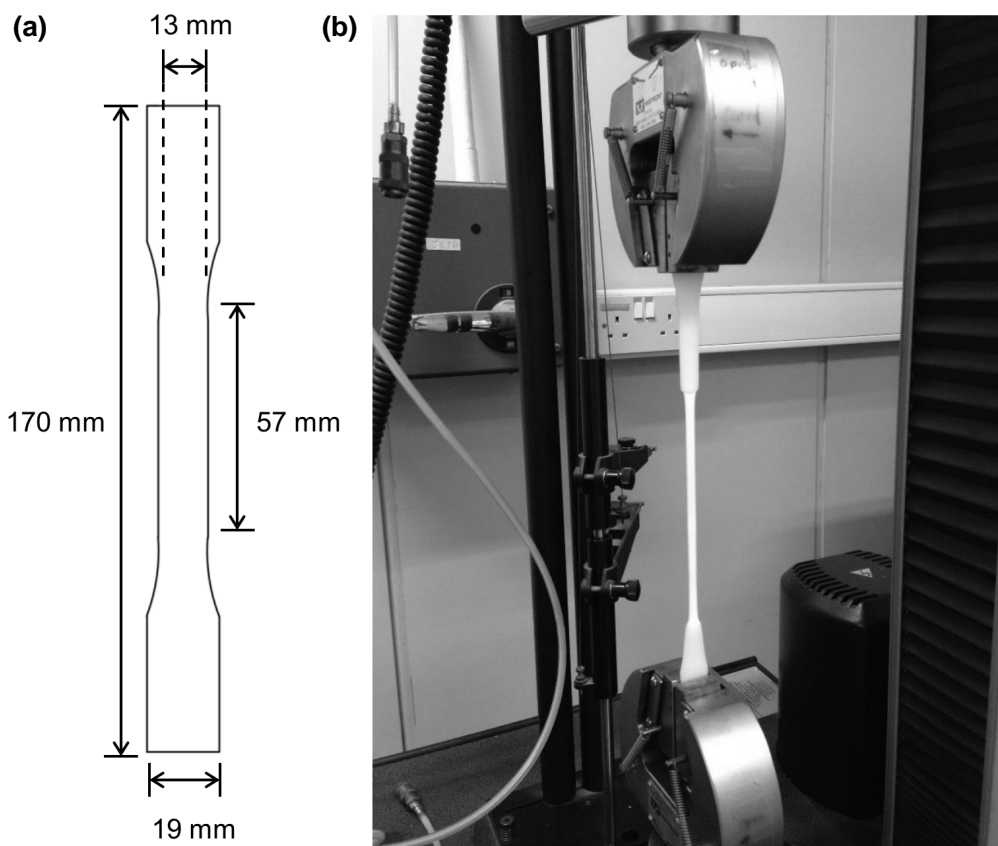

Figure 1. (a) Dimensions of the HDPE tensile bar. (b) Experimental setup for tensile tests and cold drawing of the specimens. 


\section{Results and Discussion}

\subsection{Changes in Cross-Sectional Area and Temperature}

In this study, six cross head speeds (5, 50, 80, 100, 200 and $500 \mathrm{~mm} / \mathrm{min}$ ) were examined. The HDPE specimens cold-drawn at different cross head speeds were shown in Figure 2. During cold drawing, necking of the polymer was observed. While the applied force remained almost constant during polymer stretching, the cross-section of the necking region became less than that of the remaining undrawn portion of the polymer. This was confirmed by Figure 3, in which the cross-sectional area of the cold-drawn specimen decreased significantly. During the analysis above, the specimen cold-drawn at $5 \mathrm{~mm} / \mathrm{min}$ was not taken into account. This was because at that cross head speed, failure of the specimen could not be reached even at the limit of stretching applicable by the tensile testing machine, leading to failure of determination of the final cross-sectional area in that case.

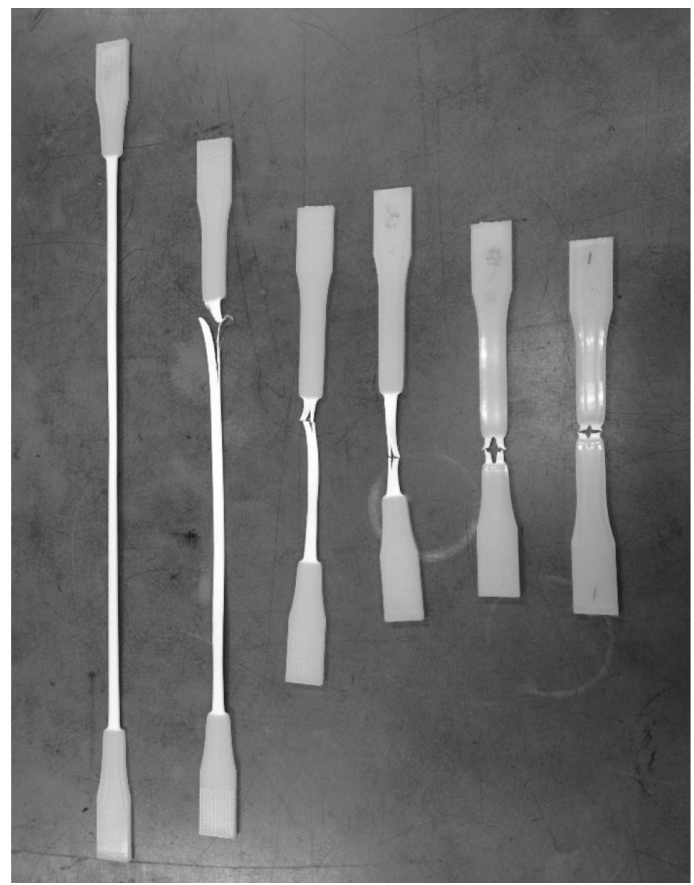

Figure 2. HDPE tensile bars cold-drawn at different cross head speeds. From the left to right, the cross head speeds used were 5, 50, 80, 100, 200 and $500 \mathrm{~mm} /$ min, respectively.

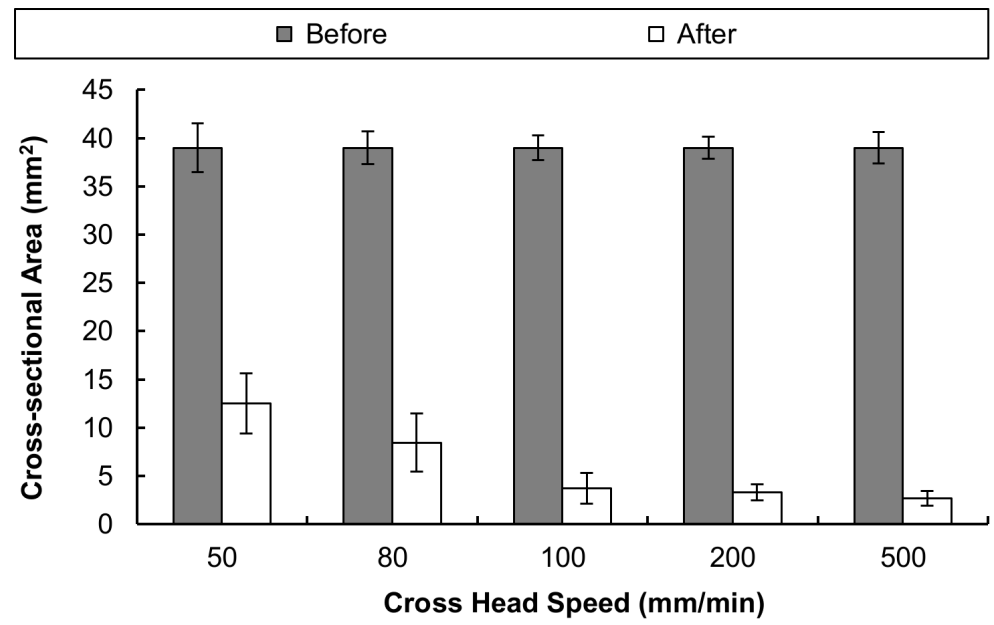

Figure 3. Changes in cross-sectional areas of the tensile bars after cold drawing. 
During cold drawing, we found that at the cross head speed of $500 \mathrm{~mm} / \mathrm{min}$, the temperature at the necking region increased. The generation of heat was hypothesized to be due to the inherent energy loss during plastic deformation. When the necking region was touched by fingers, there was an increase in the load experienced by the specimen. Such an increase in load disappeared once the fingers were removed, and the load experienced by the specimen returned to the original level (Figure 4(a)). Similar observations were found at the cross head speeds of 50, 80, 100 and $200 \mathrm{~mm} / \mathrm{min}$. Contrary to the situation above, at the cross head speed of $5 \mathrm{~mm} / \mathrm{min}$, the strain rate was low, and the temperature at the necking region decreased. This was proposed to be due to the dissipation of energy under the extremely low strain rate. Moreover, the load experienced by the specimen reduced when the necking region was touched by fingers, though such a decrease disappeared when the fingers were removed (Figure 4(a)).

\subsection{Effects of Strain Rates on the Yield Strength}

Based on the extension-load curves in Figure 4(a), the stress and strain experienced by the specimens during cold drawing were determined. The engineering stress $(\sigma)$ and engineering strain $(\varepsilon)$ were obtained by equations (1) and (2), where $F$ is the magnitude of the applied force, $A$ is the cross-sectional area of the specimen, $l_{0}$ is the initial length of the specimen, and $\Delta l$ is the change in the specimen length:

$$
\begin{aligned}
& \sigma=\frac{F}{A} \\
& \varepsilon=\frac{\Delta l}{l_{0}}
\end{aligned}
$$

Based on the engineering stress and engineering strain, the true stress $\left(\sigma_{T}\right)$ and true strain $\left(\varepsilon_{T}\right)$ were obtained by equations (3) and (4). The true stress-true strain curves were plotted in Figure 4(b), in which the yield strength tended to increase as the cross head speed increased. This suggested that the yield strength was positively related to the strain rate.

$$
\begin{gathered}
\sigma_{T}=\delta(1+\varepsilon) \\
\varepsilon_{T}=\ln (1+\varepsilon)
\end{gathered}
$$

Semi-crystalline polymers, as well as amorphous polymers, generally have the yield behavior described by the Eyring's viscosity theory [22]. Previous experiments demonstrated that under specific testing conditions, the

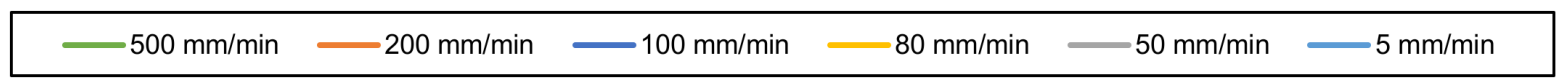
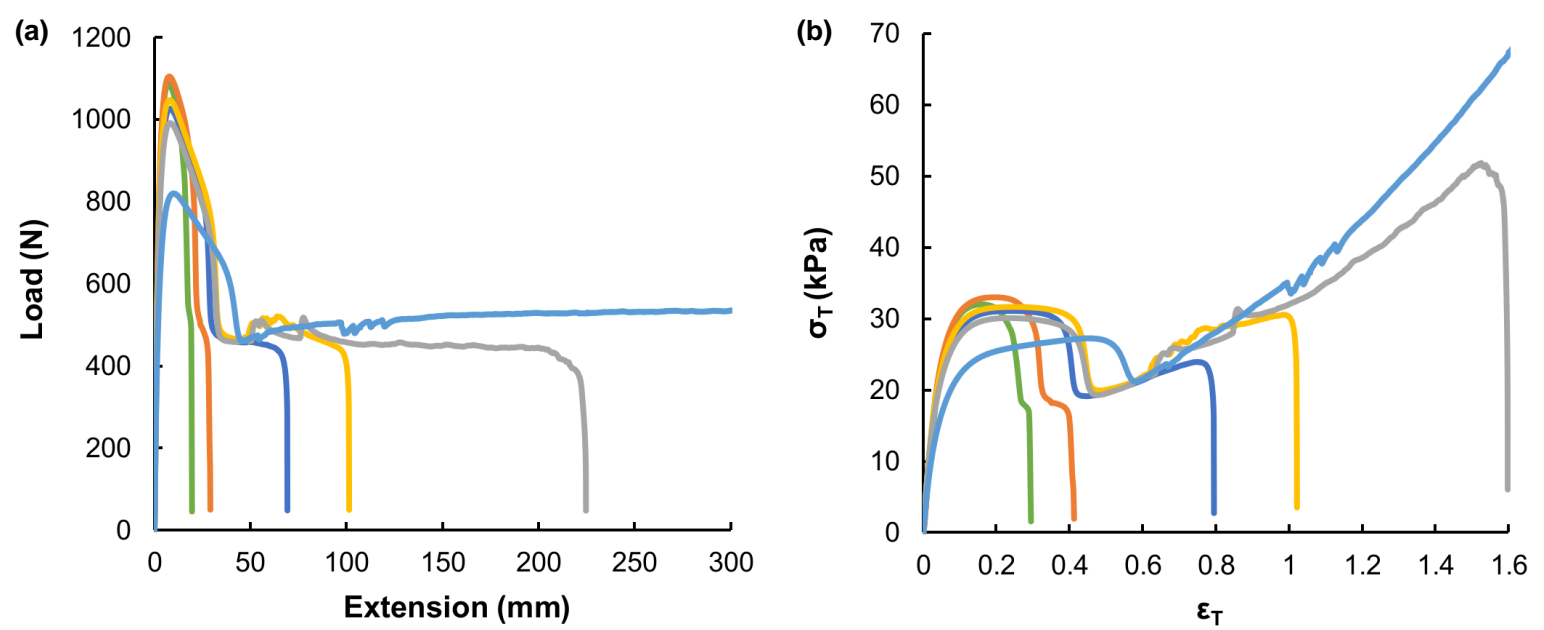

Figure 4. (a) The extension-load curves and (b) true stress-true strain curves of HDPE cold-drawn at different cross head speeds. 
ratio of yield stress and absolute temperature is in a linear relationship with the natural logarithm of the strain rate [23] [24]. Based on this relationship, the activation volume $\left(V_{0}\right)$ of the polymer can be determined by Equation (5), where $C$ is a constant, $T$ is the absolute temperature, $\varepsilon_{0}$ is activation energy, $\bar{\varepsilon}$ is the cross head speed, $\sigma$ is the yield stress, and $K$ is the Boltzmann's constant:

$$
\frac{\sigma}{T}=\frac{2 \mathrm{~K}}{V_{0}}\left[\ln (C \bar{\varepsilon})+\frac{\varepsilon_{0}}{K T}\right]
$$

By rearranging the equation, we have:

$$
\sigma=\frac{2 \mathrm{KT}}{V_{0}}[\ln \bar{\varepsilon}]+\frac{2 \mathrm{KT}}{V_{0}}\left[\ln C+\frac{\varepsilon_{0}}{K T}\right]
$$

The plot of the yield stress against the natural logarithm of the cross head speed was presented in Figure 5 . According to Equation (6), the slope of the plot is equal to $2 K T / V_{0}$, from which $V_{0}$ was approximated to be $4.98 \times$ $10^{-27} \mathrm{~m}^{3}$. As this activation volume is much larger than a single repeating unit, this suggests that the yield in HDPE may involve the cooperative motion of multiple repeating units.

\subsection{Changes in Anisotropic Mechanical Properties}

As HDPE was originally crystallized from solution in the absence of external forces during injection molding, there was no preferred orientation along which the polymer chains lie. During cold drawing, the semi-crystalline HDPE specimen underwent large-strain plastic deformation in tension. Molecular alignment of the polymer chains, therefore, occurred in the principle direction of extension parallel to the axis of the polymer. Cold drawing after the yield point was expected to lead to a strain hardening process. Otherwise, the material would break without drawing at the reduced cross-section where necking occurred. The occurrence of strain hardening, followed by an increase in anisotropy, was due to the reason that during cold drawing, the originally soft intermolecular interactions, which were manifested by the isotropic elastic properties of HDPE, were replaced by stiffer intra-molecular interactions experienced by the backbone of HDPE. The strain hardening of HDPE after cold drawing was confirmed in Figure 6, in which the hardness of the necking region was significantly higher ( $\mathrm{p}<$ 0.05 ) than that of the undrawn part. This indicated that the higher the strain provided to the polymer during cold drawing, the higher the level of anisotropy finally obtained.

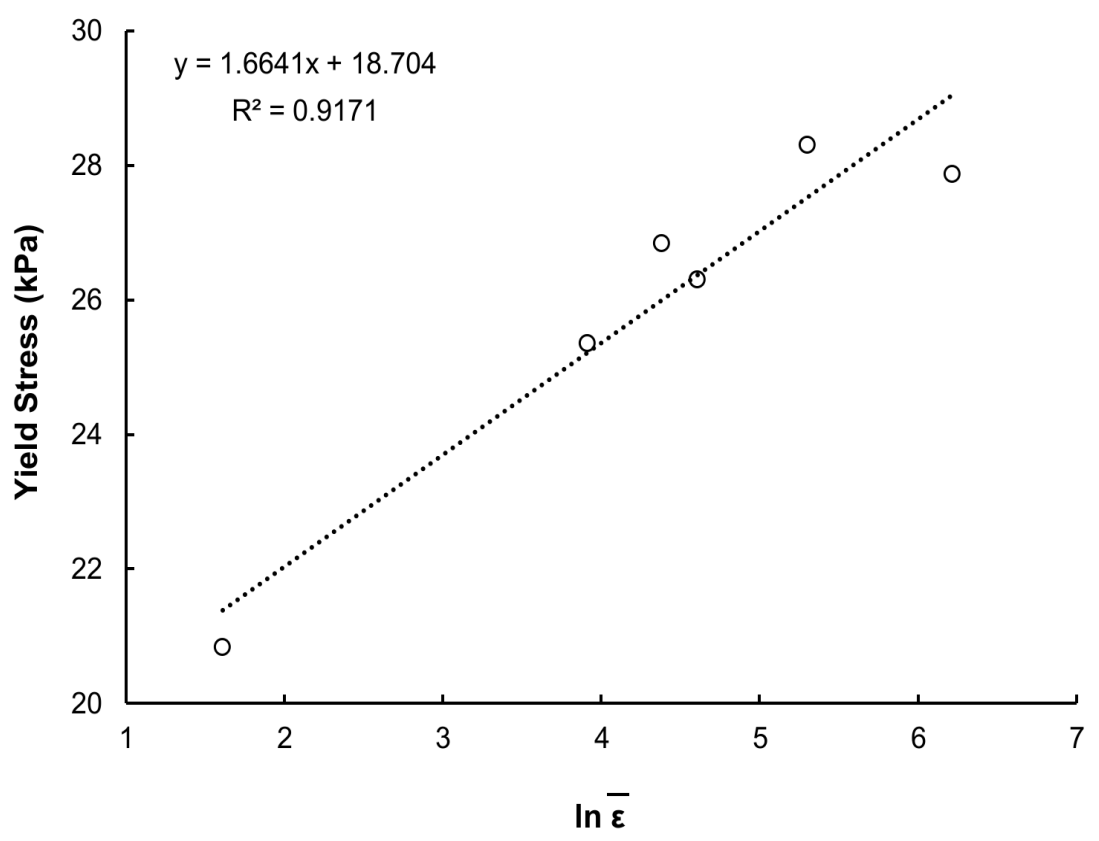

Figure 5. The plot of yield stress against the natural logarithm of the cross head speed. 


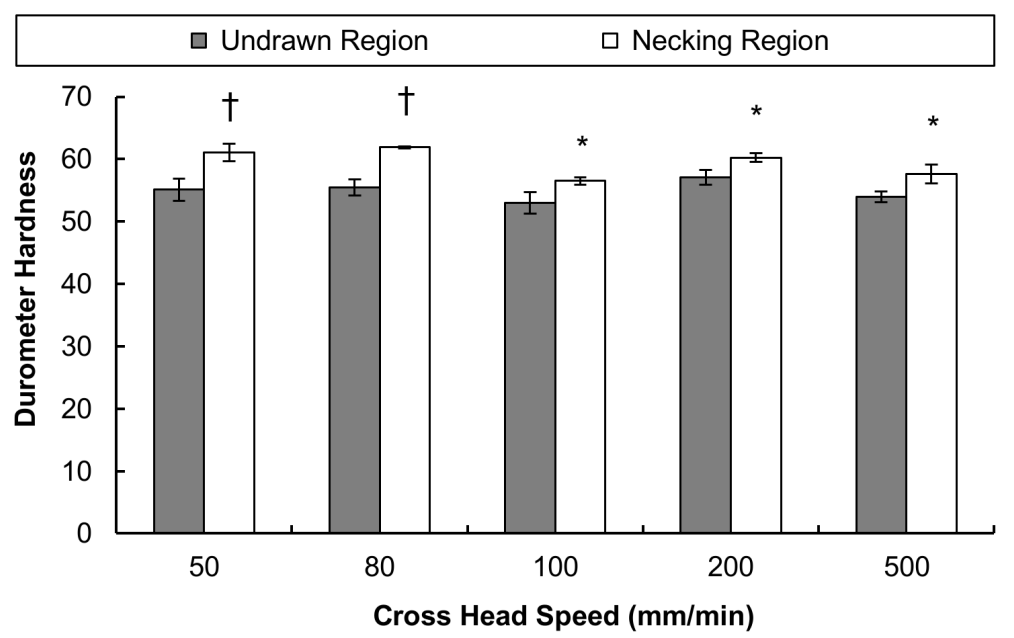

Figure 6. The durometer hardness of the undrawn and necking regions of the HDPE specimens cold-drawn at different cross head speeds $\left(\dagger p<0.01 ;{ }^{*}\right.$ p $<$ 0.05 compared to the undrawn region).

\section{Conclusion}

Polymers are one of the materials that have attracted attention due to their easy processing, biological performance and easy maintenance. In this study, we showed that the anisotropic mechanical properties of the semicrystalline polymer could be increased by the treatment of cold drawing, and the yield strength of the polymer was shown to be in a positive relationship with the strain rate. This study confirmed the feasibility of modifying polymer properties by applying tension for plastic deformation, and highlighted the importance of precise control of the strain rate during the procedure.

\section{References}

[1] Giron-Gonzalez, M.D., Morales-Portillo, A., Salinas-Castillo, A., Lopez-Jaramillo, F.J., Hernandez-Mateo, F., SantoyoGonzalez, F. and Salto-Gonzalez, R. (2014) Engineered Glycated Amino Dendritic Polymers as Specific Nonviral Gene Delivery Vectors Targeting the Receptor for Advanced Glycation End Products. Bioconjugate Chemistry, 25, 1151-1161. http://dx.doi.org/10.1021/bc5001643

[2] Lai, W.F. (2011) In Vivo Nucleic Acid Delivery with PEI and Its Derivatives: Current Status and Perspectives. Expert Review of Medical Devices, 8, 173-185. http://dx.doi.org/10.1586/erd.10.83

[3] Lai, W.F. (2014) Cyclodextrins in Non-Viral Gene Delivery. Biomaterials, 35, 401-411. http://dx.doi.org/10.1016/j.biomaterials.2013.09.061

[4] Tsai, W.B., Chen, W.T., Chien, H.W., Kuo, W.H. and Wang, M.J. (2014) Poly(dopamine) Coating to Biodegradable Polymers for Bone Tissue Engineering. Journal of Biomaterials Applications, 28, 837-848.

[5] Lu, P., Xiao, H., Zhang, W. and Gong, G. (2014) Reactive Coating of Soybean Oil-Based Polymer on Nanofibrillated Cellulose Film for Water Vapor Barrier Packaging. Carbohydrate Polymers, 111, 524-529. http://dx.doi.org/10.1016/j.carbpol.2014.04.071

[6] Gerard, M., Chaubey, A. and Malhotra, B.D. (2002) Application of Conducting Polymers to Biosensors. Biosensors and Bioelectronics, 17, 345-359. http://dx.doi.org/10.1016/S0956-5663(01)00312-8

[7] Ahuja, T., Mir, I.A., Kumar, D. and Rajesh (2007) Biomolecular Immobilization on Conducting Polymers for Biosensing Applications. Biomaterials, 28, 791-805. http://dx.doi.org/10.1016/j.biomaterials.2006.09.046

[8] Kafedjiiski, K., Foger, F., Werle, M. and Bernkop-Schnurch, A. (2005) Synthesis and in Vitro Evaluation of a Novel Chitosan-Glutathione Conjugate. Pharmaceutical Research, 22, 1480-1488. http://dx.doi.org/10.1007/s11095-005-6248-6

[9] Kast, C.E., Frick, W., Losert, U. and Bernkop-Schnurch, A. (2003) Chitosan-Thioglycolic Acid Conjugate: A New Scaffold Material for Tissue Engineering? International Journal of Pharmaceutics, 256, 183-189. http://dx.doi.org/10.1016/S0378-5173(03)00076-0

[10] Krauland, A.H., Hoffer, M.H. and Bernkop-Schnurch, A. (2005) Viscoelastic Properties of a New in Situ Gelling Thiolated Chitosan Conjugate. Drug Development and Industrial Pharmacy, 31, 885-893. 
http://dx.doi.org/10.1080/03639040500271985

[11] Schmitz, T., Grabovac, V., Palmberger, T.F., Hoffer, M.H. and Bernkop-Schnurch, A. (2008) Synthesis and Characterization of a Chitosan-N-Acetyl Cysteine Conjugate. International Journal of Pharmaceutics, 347, 79-85. http://dx.doi.org/10.1016/j.ijpharm.2007.06.040

[12] Casas, F., Alba-Simionesco, C., Lequeux, F. and Montes, H. (2006) Cold Drawing of Polymers: Plasticity and Aging. Journal of Non-Crystalline Solids, 352, 5076-5080. http://dx.doi.org/10.1016/j.jnoncrysol.2006.05.034

[13] Cheng, S.W. and Wang, S.Q. (2014) Elastic Yielding after Cold Drawing of Ductile Polymer Glasses. Macromolecules, 47, 3661-3671. http://dx.doi.org/10.1021/ma500570w

[14] Fakirov, S., Bhattacharyya, D., Lin, R.J.T., Fuchs, C. and Friedrich, K. (2007) Contribution of Coalescence to Microfibril Formation in Polymer Blends during Cold Drawing. Journal of Macromolecular Science, Part B: Physics, 46, 183193. http://dx.doi.org/10.1080/00222340601044375

[15] Gutierrez, M.C.G., Karger-Kocsis, J. and Riekel, C. (2002) Cold Drawing-Induced Mesophase in Amorphous Poly(ethylene naphthalate) Revealed by X-Ray Microdiffraction. Macromolecules, 35, 7320-7325. http://dx.doi.org/10.1021/ma020468h

[16] Osaka, N., Yanagi, K. and Saito, H. (2013) The Optical Transparency and Structural Change of Quenched Poly(vinylidene fluoride) Caused by Cold-Drawing. Polymer Journal, 45, 1033-1040. http://dx.doi.org/10.1038/pj.2013.26

[17] Takahiro, M. (2002) Theoretical Analysis of Unstable Necking Process in Cold Drawing of Poly(ethylene telephthalate). Kobunshi Ronbunshu, 59, 517-526. http://dx.doi.org/10.1295/koron.59.517

[18] Yang, X.Z. and Sun, J. (2002) Coil Extension Stage in the Cold Drawing of Glassy Polymers. Journal of Polymer Science Part B: Polymer Physics, 40, 2646-2652. http://dx.doi.org/10.1002/polb.10325

[19] Venkatraman, S., Poh, T.L., Vinalia, T., Mak, K.H. and Boey, F. (2003) Collapse Pressures of Biodegradable Stents. Biomaterials, 24, 2105-2111. http://dx.doi.org/10.1016/S0142-9612(02)00640-3

[20] Hashemi, S. (1997) Fracture Toughness Evaluation of Ductile Polymeric Films. Journal of Materials Science, 32, 1563-1573. http://dx.doi.org/10.1023/A:1018582707419

[21] Devi, R.R. and Maji, T.K. (2002) Studies of Properties of Rubber Wood with Impregnation of Polymer. Bulletin of Materials Science, 25, 527-531. http://dx.doi.org/10.1007/BF02710543

[22] Eyring, H. (1936) Viscosity, Plasticity and Diffusion as Examples of Absolute Reaction Rates. The Journal of Chemical Physics, 4, 283-291. http://dx.doi.org/10.1063/1.1749836

[23] Bauwens-Crowet, C., Bauwens, J.C. and Homès, G. (1969) Tensile Yield-Stress Behavior of Glassy Polymers. Journal of Polymer Science Part A-2: Polymer Physics, 7, 735-742. http://dx.doi.org/10.1002/pol.1969.160070411

[24] Bauwens-Crowet, C., Bauwens, J.C. and Homès, G. (1972) The Temperature Dependence of Yield of Polycarbonate in Uniaxial Compression and Tensile Tests. Journal of Materials Science, 7, 176-183.

http://dx.doi.org/10.1007/BF02403504 